\title{
Prosthetic valves and the unending quest for the holy grail
}

\author{
Paul Kurlansky, MD
}

See related article on pages 1262-9.

In 1952, Dr Charles Hufnagel successfully implanted the first prosthetic heart valve-a sutureless methyl methacrylate cylinder containing a polyethylene ball held in place in the proximal descending thoracic aorta by multipoint steel fixation rings (Figure 1). The 30-year-old woman with rheumatic aortic insufficiency had clinical improvement and died 11 years later of other causes. Subsequent reports documented complications and late deaths associated with thromboembolism, dehiscence, infection, and erosion. ${ }^{1,2}$ Since those pioneering efforts, the introduction of cardiopulmonary bypass into routine practice, advances in both mechanical and bioprosthetic engineering, progressive decline in surgical mortality, and the recent introduction of transcatheter technologies and aortic valve repair techniques have dramatically transformed aortic valve surgery. Efforts to create a living valve substitute have been scientifically intriguing but clinically elusive. Pulmonary autografts are technically demanding, incur the need for right-sided prosthesis or homograft, and in most adult applications bear little benefit compared with alternatives. Homografts have limited availability, as well as concerns regarding longevity and calcification. In brief, despite remarkable progress, surgeons and patients are still left with the choice between a mechanical prosthesis, with reliable durability and hemodynamics but the requirement for lifelong anticoagulation, and a bioprosthesis, which is subject to tissue degeneration but does not necessitate long-term anticoagulation. More biocompatible materials and improved design features, as well as home monitoring devices, have reduced the degree of anticoagulation required for mechanical prostheses. ${ }^{3,4}$ Even with careful monitoring, however, international normalized ratios tend to fall outside the "therapeutic range" more than onethird of the time, and that range is designed merely to minimize the competing risks of bleeding and thromboembolism while eliminating neither. Pharmacogenetically

From the Department of Surgery, Columbia University, New York, NY.

Disclosures: Author has nothing to disclose with regard to commercial support.

Received for publication Feb 9, 2015; accepted for publication Feb 9, 2015; availabable ahead of print March 18, 2015.

Address for reprints: Paul Kurlansky, MD, Columbia University, Surgery, Black Building 210,650 W 168th St, New York, NY 10032 (E-mail: pk2245@cumc. columbia.edu).

J Thorac Cardiovasc Surg 2015;149:1242-3

$0022-5223 / \$ 36.00$

Copyright (c) 2015 by The American Association for Thoracic Surgery

http://dx.doi.org/10.1016/j.jtcvs.2015.02.014

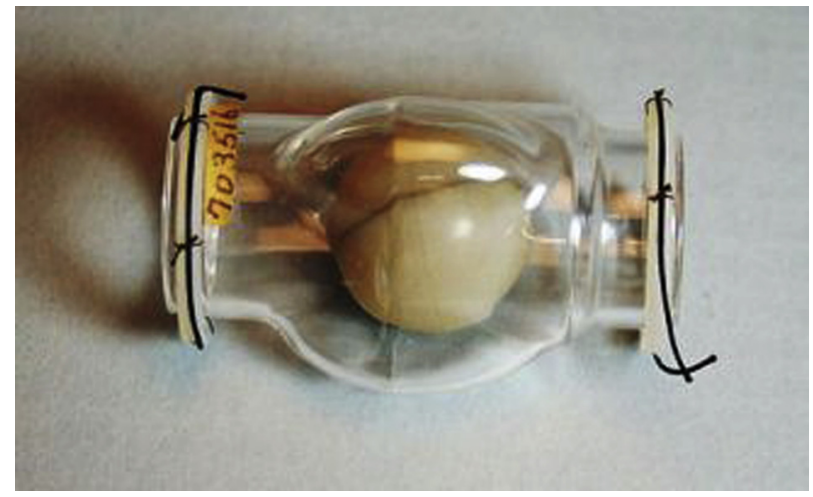

FIGURE 1. Original Hufnagel valve.

based dosing may improve time in the therapeutic range, but its clinical utility remains to be proved. ${ }^{5}$ On the other hand, advances in tissue engineering and design, as well as decreasing risk of reoperative surgery, have combined to make bioprostheses a more attractive alternative. Use of bioprostheses in the aortic position has doubled during the past decade, now surpassing that of mechanical valves, with increasing use in younger patients. ${ }^{6}$

Corroborating these developments, Isaacs and colleagues $^{7}$ in this issue of the Journal report their study of recent trends in aortic valve replacement. In an examination of 1998 to 2011 data from the National Inpatient Sample, they found not only that use of bioprostheses had increased dramatically but that bioprosthetic aortic valve replacement was associated with lower inhospital mortality compared with mechanical prostheses. ${ }^{7}$ Moreover, centers performing higher volumes of procedures were more inclined to select bioprostheses and to have a lower mortality. These results are somewhat startling, in view of several well-conducted prospective, randomized studies that have shown similar mortality with an earlier generation of mechanical versus biologic prostheses. ${ }^{8-10}$ The findings are, however, not unique, with very similar results recently reported in the Medicare population. ${ }^{11}$

The question raised by these studies is compelling-is it the valve, or is it the surgeon?

Although designed to reflect current clinical practice, the National Inpatient Sample is vulnerable to the welldescribed limitations of administrative databases. Although Isaacs and colleagues ${ }^{7}$ were careful to create well-determined propensity-matched groups, which corroborated their findings, the limited reliability of clinical parameters recorded did not permit formal risk adjustment. Coding may have been an issue, because the International Classification of 
Diseases, Ninth Revision, Clinical Modification code 35.22 is somewhat more ambiguous than 35.22 , which specifies a tissue implant, because $29 \%$ of the " 35.22 " mechanical valve recipients were 75 years old or older, a somewhat unusual finding. Moreover, the impact of limiting survival to the available in-hospital data rather than the now-standard 30-day benchmark may have biased the results, because a higher percentage of bioprosthetic versus mechanical prosthetic recipients had a "nonroutine" discharge, even among the matched groups. Limitations aside, if we postulate that the difference in mortality was truly valve related, there should be a signal in the data that would reflect a higher morbidity in the mechanical group. Paradoxically, the complication rate, including bleeding, was actually higher in the bioprosthetic recipients. Mortality among those patients with complications, or "failure to rescue," however, was actually higher in the mechanical than in the bioprosthetic group. Increasingly recognized as an important metric of quality, failure to rescue studies have demonstrated considerable variation in surgical mortality despite similar incidence of complications. ${ }^{12}$ In essence, although the avoidance of complications is certainly important, it appears that their timely recognition and management may have a greater impact on patient survival. The association of larger-volume centers with a lower failure to rescue described in this study is not surprising. What does remain enigmatic is the predilection of higher performing centers for bioprosthetic aortic valves, perhaps related a lower concern for the risks of reoperation. The core of this association remains the topic of future research. The data, however, suggest that it is not that bioprosthetic valves carry a lower operative risk than their mechanical counterparts, but rather that the quality of care rather than the choice of prosthesis determines the patient's operative outcome.

\section{References}

1. Hufnagel CA, Harvey WP, Rabil PJ, McDermott TF. Surgical correction of the aortic insufficiency. Surgery. 1954;35:673-83.

2. Popma BH, Goldstein AS, Jacques J, Guenter CA. Double prosthetic aortic valve. Late aortic erosion by Hufnagel valve. Chest. 1976;70:660-2.

3. Koerfer R, Reiss N, Koertke H. International normalized ratio patient selfmanagement for mechanical valves: is it safe enough? Curr Opin Cardiol. 2009;24:130-5.

4. Puskas J, Gerdisch M, Nichols D, Quinn R, Anderson C, Rhenman B, et al; PROACT Investigators. Reduced anticoagulation after mechanical aortic valve replacement: interim results from the prospective randomized $\mathrm{On}-\mathrm{X}$ valve anticoagulation clinical trial randomized Food and Drug Administration investigational device exemption trial. J Thorac Cardiovasc Surg. 2014;147:1202-10; discussion 1210-1.

5. Tang T, Liu J, Zuo K, Cheng J, Chen L, Lu C, et al. Genotype-guided dosing of coumarin anticoagulants: a meta-analysis of randomized controlled trials. $J$ Cardiovasc Pharmacol Ther. January 8, 2015 [Epub ahead of print].

6. Barnett SD, Ad N. Surgery for aortic and mitral valve disease in the United States: a trend of change in surgical practice between 1998 and 2005. J Thorac Cardiovasc Surg. 2009;137:1422-9.

7. Isaacs AJ, Shuhaiber J, Salemi A, Isom OW, Sedrakyan A. National trends in utilization and in-hospital outcomes of mechanical versus bioprosthetic aortic valve replacements. J Thorac Cardiovasc Surg. 2015;149:1262-9.

8. Hammermeister K, Sethi GK, Henderson WG, Grover FL, Oprian C, Rahimtoola SH. Outcomes 15 years after valve replacement with a mechanical versus a bioprosthetic valve: final report of the Veterans Affairs randomized trial. J Am Coll Cardiol. 2000;36:1152-8.

9. Oxenham H, Bloomfield P, Wheatley DJ, Lee RJ, Cunningham J, Prescott RJ, et al. Twenty year comparison of a Bjork-Shiley mechanical heart valve with porcine bioprostheses. Heart. 2003;89:715-21.

10. Stassano P, Di Tommaso L, Monaco M, Iorio F, Pepino P, Spampinato N, et al. Aortic valve replacement: a prospective randomized evaluation of mechanical versus biological valves in patients ages 55 to 70 years. J Am Coll Cardiol. 2009;54:1862-8.

11. Du D, McKean S, Kelman JA, Laschinger J, Johnson C, Warnock R, et al. Early mortality after aortic valve replacement with mechanical prosthetic vs bioprosthetic valves among Medicare beneficiaries: a population-based cohort study. JAMA Intern Med. 2014;174:1788-95.

12. Ghaferi AA, Birkmeyer JD, Dimick JB. Variation in hospital mortality associated with inpatient surgery. $N$ Engl J Med. 2009;361:1368-75. 